\title{
Culture and motherhood: findings from a qualitative study of East Asian mothers in Britain
}

\author{
Hyun-Joo Lim and Tina Skinner
}

\begin{abstract}
This article focuses on the possible impacts of Confucianism on the experiences of middle-class East Asian women with dependent children in Britain. By using the concept of 'intersectionality', it aims to understand the ways in which mothering identity intersects with class and East Asian cultural identity in the British context, and how identities emerge through this interaction. The study was based on in-depth interview data collected from 20 first-generation East Asian mothers living in Britain, and suggests that East Asian mothers in this study appear to share a discernible trace of Confucianism, including a strong emphasis on education, alongside a high value placed on seniority, and children as a mother's possession. These Confucian values were portrayed by the interviewees as salient in constructing their mothering identities. Simultaneously, however, certain aspects of British culture were also perceived to be significant in their mothering, in that they appeared to provide the interviewees with opportunities to question and modify their cultural values.
\end{abstract}

Key words: British culture; Confucianism; East Asian identity; intersectionality; mothering identity 


\section{Introduction}

There are a large number of publications exploring the mothering experiences of women in Britain (e.g. Bailey 2000; Vincent et al. 2004). However, there is a limited amount of literature on the experiences of ethnic minority women residing in Britain, particularly those of mothers with East Asian heritage. Several studies have been conducted regarding the lives of East Asian women living in East Asian countries (Chan 2008; Hirao 2001). Though these make a significant contribution towards gaining an insight into these groups of women, they are limited in providing direct contextual information on the experiences of East Asian mothers in Britain.

Dale, Lindley and Dex (2006), drawing on their examination of the British Quarterly Labour Force Survey (QLFS), suggest that the notions of mothering and its subsequent impact on women's employment patterns differ, contingent upon their ethnic origins. Whilst this research has made a significant contribution to highlighting the importance of ethnicity in individual women's experiences of mothering, it has not investigated deeply the lived experiences and perceptions of ethnic minority women. Indeed, the examination of official survey data has resulted in the exclusion of certain ethnic minority groups of women, such as Japanese and Korean, who are not officially categorised in British ethnic groups.

In order to fill in the gap in existing literature, this paper aims to present findings from 20 interviews with middle-class East Asian women from China, Hong Kong, South Korea and Japan; countries that have been heavily influenced by Confucianism. The teachings of Confucianism has spread to these East Asian countries since the territorial and cultural expansion of the Han dynasty between 206 BCE and $220 \mathrm{CE}$ and had a substantial impact on their cultural formation. As a result, whilst East Asian countries are divergent in economic and political terms (Ebrey et al. 2006), they have historically shared cultural similarities (Yi and Nauck 2006). This paper explores similarities and differences in mothering among first generation East Asian mothers in Britain.

In order to analyse the experiences of women with East Asian heritage the concept of intersectionality is employed. Rather than seeing different social categories, such as gender and ethnicity, as additive, intersectionality places emphasis on the interaction between various social identities and the ways in which this process produces qualitatively different effects. Drawing on this, our data suggests that the 
interplay of mothering with similar ethnic and class positions produced similar experiences that East Asian mothers in Britain perceive to be unique, and which they distinguish from the majority of white British mothers as well as mothers still living in East Asian countries.

\section{Confucianism and its continuing impact on East Asian women's lives}

Confucianism refers to the ancient Chinese tradition, which supports the belief that a 'natural' hierarchy is the fundamental means to achieve all human relationships and generate harmony to all of society (Oldstone-Moore 2003: 9). The most significant relationships in Confucian teachings are those between parents and child. Filial piety is considered to be the lynchpin of Confucian virtue (Keum 2003). It requires parents to provide a child with education, care, and moral formation while a child has an obligation to be obedient and respect their parents (Lau 1979). A husband and wife also have a duty to look after each other, with the husband taking the role of provider and the wife taking responsibility for the household. Alongside these principles, Confucian ideals include a high value placed on seniority (Sung 2003) and dedication to education (Chen 1986). According to Inoguchi and Shin (2009:184), Confucian principles give primacy to 'family and community over the individual, discipline and hierarchy over freedom and equality, and consensus and harmony over diversity and conflict'.

Although some evidence suggests that the impact of these Confucian values on East Asian countries is weakening (Brinton et al. 1995; Wu 2007), a number of studies have demonstrated that Confucian beliefs continue to be highly influential in the everyday lives of people living in East Asian countries, particularly women with dependent children (e.g. Chan 2008; Sung 2003). For example, Sung's (2003) research on the impact of Confucian conventions on married women's experiences of combining employment and care in South Korea confirmed the pervasive impact of the Confucian legacy on the lived experiences of many working mothers in this country: employed mothers received little help from their husbands in childcare and thus half of them relied on either their mothers or mothers-in-law. Drawing on her data, Sung (ibid.) asserted that, despite a recent increase in women's economic activities, Korean women's lives are still strongly shaped by traditional Confucian values, such as gendered norms. Similarly, Chan (2008), based on her study of motherhood ideals and practices in Hong Kong, suggests that mothers are considered to have a major responsibility for childcare 
and their children's academic achievement in Hong Kong where strong emphasis is placed on education. Hirao (2001), drawing on her research on the impact of educational demands on the construction of motherhood ideology in Japan, points out the immense level of expectations put on mothers to provide excellent education for their children. Based on the above, it can be suggested that Confucianism appears to have a critical impact on individual women's lives in East Asian countries. However, there remains a question regarding how Confucian values and norms are perceived to affect East Asian women in socio-cultural contexts outside East Asian countries.

\section{Conceptualising culture}

As can be seen from the above, cultural values play a vital role in shaping the experiences of women with children. Williams (1981) suggests that cultural practice guides individuals to behave in a certain way, which enables the maintenance of social order in a given society. For Williams (ibid.: 13) culture is seen as 'the signifying system' through which cultural norms and values are transmitted and regenerated. In this sense, whilst the experiences of mothering are individual and subjective, they are simultaneously drawn from a 'common culture of motherhood' available to women in a particular social and cultural context (Thomson et al. 2011: 8). Miller (2005: 29) proposes that women's experiences of mothering are shaped by what Jordan (1993) calls 'authoritative knowledge' developed within a particular social environment. Drawing on her narrative study of mothering in Western and Eastern societies, Miller goes on to say that divergent modes of 'authoritative knowledge' exist in different cultures (e.g. UK and Bangladeshi). According to Miller (2005), women's understandings around mothering are heterogeneous, depending on their cultural positioning.

While maintaining the importance of shared culture in constructing the identity of migrant individuals, Hall (1990) proposes that we should not fall into cultural essentialism by treating culture as something fixed or unchangeable. Hall (1990: 226) suggests that cultural identities of migrant individuals are not solidly attached to their past although they may continue to retain a tie with their homeland through 'memory, fantasy, narrative and myth'. Instead, he argues that their identities should be regarded as constantly produced and reproduced through diversity within new cultural settings. In this sense, the notion of hybridity may offer a useful medium to examine the identity 
construction of migrant individuals. Hall (1988) describes hybridity as the reconstruction of identity within the context of migration, drawing both from the homeland and from the society of settlement. For example, the study of Erel (2009) on Turkish migrant women in Germany and Britain demonstrates how identities of migrant women are constructed and reconstructed through the blend of other cultures within the host society. By using their agency her participants actively recreated what it meant to be Turkish women in Germany or Britain by combining divergent cultures.

Founded on these, culture in this paper is conceptualised as 'the signifying system' (Williams 1981) that shapes individual women's notions and experiences of mothering within a particular context. Concurrently, drawing on Hall (1990), the concept of hybridity will be used in understanding the experiences of first generation East Asian mothers in Britain. In the ensuing sections we will present how the perceived 'common culture' of first generation East Asian mothers affects their perception and practices of mothering in Britain. We will also illustrate how migration is perceived to offer opportunities for obtaining and utilising different forms of culture from their country of origin, enabling them to experience 'hybridised' forms of mothering.

\section{Theoretical framework}

Freeden (2003) proposes that individuals make sense of their surrounding world through the lens of a particular ideology. Hence, we understand mothering through a set of beliefs that are presented to us within a particular historical and cultural milieu (Lawler 1996). This implies that ideology entails subjective characteristics that promote a particular set of ideas over others (Glenn 1994). In Western societies the dominant idealised image of a mother is that of a woman who selflessly gives labour, resources and love in a child-centred manner (Hays 1996). This dominance of intensive mothering was also found in East Asian countries where Confucian patriarchy is thought to have a strong influence on women's lives (Hirao 2001).

However, although women may appear to share similarities in their mothering based on gender, mothering is a historically and culturally specific phenomenon (Glenn 1994). Existing literature has demonstrated that experiences of mothering can vary between different cultures (Miller 2005) as well as within cultures (Lim 2012). The study by Lim (2012), based on first generation East Asian mothers in England, illuminates heterogeneity in motherhood ideology and its impact on the patterns of 
mothers' employment. Although the impact of Confucian patriarchal ideology remained relatively firm for the majority of East Asian women in her study, the women presented different understandings of good mothering, depending on their country of origin (e.g. China or Korea). On a slightly different note, the research of Erel (2002) on Turkish migrant mothers in Germany highlights the complex and diverse configuration of mothering that transgresses the traditional image of mothers who provide primary care for their children as well as transmit their cultural heritage to them. According to Erel, many of her participants migrated either in order to avoid social and familial pressures as a result of divorce or to support their children financially, leaving them to the care of others in their home country. Erel (2002) suggests the stereotyped portrayal of mothers who play a conventional primary caring role is limited in explaining the lives of Turkish migrant women in her study. These studies illuminate the importance of intersecting relations between various social factors in shaping the experiences of migrant mothers.

The term 'intersectionality' refers to 'interlocking' relations between gender and other social categories, such as ethnicity and class. According to Anthias and Yuval-Davis (1983: 62-63), 'race, gender, and class cannot be tagged onto each other mechanically for, as concrete social relations, they are enmeshed in each other and the particular intersections involved produce specific effects' (see also Andersen and HillCollins 2004). Thus, rather than viewing identity in a simplistic manner, we need to understand it as a more complicated and dynamic process. Consonant with this, Valentine (2007) underscores the fluid nature of identity formation, produced through the intersection of multiple forms of identity, as well as demonstrating the active participation of the individual in constructing their own biographies. Drawing on this literature and our interview data, we argue that the mothering identities of East Asian women in Britain should be understood in a specific context of intersecting identities. In other words, their location as East Asian immigrants in Britain adds a new dimension to their identity as they observe different mothering norms and practices in Britain.

Whilst intersectionality is immensely useful in analysing the interlocking relations of identity, the way individuals make sense of themselves is often through differentiation from the perceived Other (e.g. Hays 1996). In this sense, 'othering' is an instrumental tool for social groups to define their identity through marking the difference and drawing symbolic boundaries, dissociating themselves from the other group (Douglas 1966). According to Hall (1997), 'othering' involves the process of stereotyping, in which the Other is seen in relation to a set of fixed, simple, innate 
characteristics. Hall (ibid.) simultaneously points out the ambivalent characteristics of difference, which signify both positive and negative meanings: for example, in this paper we will draw on evidence to suggest that some East Asian mothers try to dissociate themselves from the perceived negative characteristics of British mothers, yet simultaneously copy certain aspects of 'the British way' of mothering.

Similarly, Hays (1996) in her study in the USA highlights mothers' involvement in the negative depiction of the Other mothers who had a different work status from them, predicated upon the contradictory logic between the self-centred marketplace and the selflessly giving intensive motherhood in contemporary Western society. According to Hays, despite this tension between working and stay-home mothers, all mothers in her study ultimately succumbed to intensive mothering ideology. Thus, all mothers, regardless of their employment status, engaged in child-centred practices in which children's happiness was primary.

Although this ideal of intensive mothering dominates the experiences of mothers in Western society, in this paper we suggest that East Asian mothers in Britain are likely to differ due to their exposure to divergent cultural influences, such as Confucianism. Thus, for first generation East Asian mothers who possess a different cultural heritage from the majority of white British mothers, the way they perceive white British mothers might play a pivotal role in understanding their life as ethnic minority mothers in Britain.

\section{Methods}

The data was collected through in-depth interviews with 20 first generation East Asian women living in England with at least one dependent child under the age of 11. The recruitment process was undertaken by visiting playgroups, private institutions for afterschool tutoring and East Asian language schools, by directly approaching potential participants and snowballing. The project was explained to the potential participants, with emphasis on voluntary participation. Informed consent forms were distributed to the agreed participants before the interview via emails. All of the participants are first generation migrants, whose duration of living in England ranges from one to 15 years. Six women were married to white British men, one to a white French man, and 13 to men of East Asian origin. The participants were based in the South of England, where there were East Asian communities, including Bath, the Korean town of New Malden in 
Surrey, and the Chinese community in Southampton. In this respect, many of the participants were part of local ethnic and/or national networks. They are composed of nine women from mainland China, three from Japan, two from Hong Kong, and six from South Korea. Four participants were in their 20s; 12 were in their 30s; three were in their 40s; and one in her 50s. Sixteen women were employed while four were stayhome mothers. Otherwise, the participants were a relatively homogeneous group, comprised of women from middle-class backgrounds with the dominant number of them (16) having the minimum of a degree level qualification: one $\mathrm{PhD}$; seven Master's; eight Bachelor's; one diploma; two A-level equivalent qualifications; and one GCSE. Ten women came to Britain to study; eight to accompany spouse; and two to work. All the respondents were married and living with their husbands.

The data was collected through the combination of questionnaires and in-depth interviews. The questionnaire was used to gather general background information on the participants, such as educational qualifications and occupations. The main data collection method used was semi-structured face-to-face in-depth interviews. The interviews were carried out by one of the authors who is a first generation migrant East Asian woman herself (South Korean). The interviews took between one and two hours. Most of the interviews were held in the participants' home. All the interviews were tape-recorded and transcribed fully. The majority of the interviews were carried out in English, excluding interviews with six Korean women. The Korean interview extracts were translated into English by the interviewer, who is proficient in both languages. In order to protect anonymity, pseudonyms are used. Since this study focused on the ways their East Asian cultural heritage might affect their mothering experiences, the following question regarding culture was included in the design of the semi-structured interview: 'in what ways (if any) do you think your cultural background as Chinese (Korean or Japanese) has affected the way you raise your child(ren)?' The interviewees were given opportunities to answer this open-ended question in whichever way they wanted. Given that interview data is a co-creation between the interviewer and interviewee (Mishler 1986), the subject position of the interviewer as a first generation East Asian woman played an important part in the production of the interview. Her insider position as East Asian helped the smooth process of interviews with the participants. This also enabled her to understand more easily certain East Asian cultural aspects that the participants referred to. In this sense, the interviewer's interpretation and contribution to the findings as well as the presentation of the data form a crucial 
part of this study (Devault 1990). However, simultaneously her insider position might also have become a hindrance, making her overlook some accounts of the participants or misinterpret them (Skinner 2012). This potential setback was tackled by reflecting on the pre-understanding of the interviewer (see Stenbacka 2001). This was also strengthened by the input from the other researcher who was able to offer different versions of interpretation of the data as an 'outsider' (white British female).

\section{Findings}

\section{The importance of education}

A principal theme identified in our analysis of the data was a high value placed upon education and hard work. This was portrayed by interviewees as commonly found in East Asian countries. 'Eastern people, we always try to persuade children to study hard and go to a good university,' stated Caroline, an employed mother of a five year old child. As a possessor of a university degree from China, she came to accompany her Chinese husband after he got a job in England eight years ago. For some mothers, even if this seemed diluted through their life in Britain, there was still a perception of a strong emphasis on education, which they linked to the culture of East Asia or their country of origin. This is illustrated in the account of Anne, a home-stay Korean mother of one child aged five. She came to Britain 11 years ago to study, gained a degree, and got married to a British man:

My husband and I both think Jang should naturally go to university or we want to support him even more. In that regard, because I'm Korean, I have more desire for Jang's education because I'm a Korean mother.

A similar sentiment echoes in the talk of Julia, an employed mother of two children aged five and 12 from China, who originally came to study in Britain, obtained a Master's degree and got married to her British husband:

You know, homework, homework. If he doesn't do that, it really upsets me more than my husband. I really want him to do more all the time...the majority of my Chinese friends do the exactly same thing...My friends in London, every time we meet up, they all say, "Oh, my daughter's got this this school," which is like one of number one or two state school. Their children are basically doing so well. Deep down I would love to see my children perform like this as well, really envious. 
For Anne having a high educational aspiration for her child was perceived to be a 'natural' part of being a Korean mother. In a similar vein, Julia's extract suggests that zeal for education was considered to be the epitome of being a Chinese mother, as exemplified by the story of her other Chinese friends. Thus, as a mother with Chinese heritage she suggested she had more expectations of her son's academic achievement than her British husband. Such enthusiastic attitudes towards education are also reflected in the talk of other mothers who perceived that their approach to education was different from the majority of white British mothers. The following is the account of Kate, an employed Japanese mother of two children aged three and six, who gained a diploma from Japan, came to Britain as a voluntary worker 12 years ago and got married to a British man:

At the moment I'm teaching Japanese to kids and some of British mothers think, during the summer, kids should have time off to just enjoy. Whereas, in the Japanese way, it is advantageous to catch up with what you haven't done at school, do something else to learn [during holidays]...

Consonant with this, the account of Fay, an employed mother of one child aged two from China, suggests a perceived difference in education between China and Britain. Fay came to Britain to study five years ago and obtained a Master's degree. After completing her study, she got married to her British husband:

Chinese very much emphasise education...there is a playgroup and I went there two weeks ago and asked them, "What do you teach them?" That's a very common question in China. They said, "We don't specially teach them. They learn from play." I think that's the significant difference. So here it's more like they're trying to let children learn from practice, but in China children learn from books. You can see children who can recite Chinese poems when they're five years old in China.

According to Kate's depiction, making children study even during holidays was a very 'Japanese way', significantly different from the 'British way'. Consistent with this, Fay's talk illuminated what she saw as 'the Chinese way' of education for young children, focused on book based learning and memorising text, which she put in stark contrast to what she saw as 'the British approach', which let children develop intellectual ability gradually through play. These accounts are reminiscent of the 
Confucian tradition in which literature or written texts are highly revered (Keum 2003). As if following Confucius' teachings, East Asian children were depicted as learning in a regimented style of education from a very young age, in which mothers played the prime role as a manager and organiser. However, it is important to note that none of the interviewees directly referred to Confucianism, they referred instead to a more generic notion of culture.

Accounts of some mothers also revealed their emotional investment in their children's education and future in terms of doing their best and achieving high. This was described as contrasting with their perception of 'British' mothers whose priority was primarily portrayed as children's happiness, irrespective of whatever kinds of job they do in life. For instance, it is suggested in the talk of Song, a degree educated, employed mother from Korea with one child aged five. She came to accompany her Korean husband, who was studying a PhD in Britain, four years ago:

I talked to a British mother about her child's future. In this country...the general atmosphere is, we have a cook [at work] and I asked her whether she wanted her child to be a cook, and she said "if he wanted, yes." Not in a cynical way unlike Korean mothers. She said "Even if he worked as a Tesco assistant, as long as he is happy, I don't mind." However, I'm not like that and I hope Dongsu at least goes to university. Because I'm a Korean mother, going to university is necessary and I feel I should push him a bit until he goes to university.

For many of the East Asian mothers we interviewed, the child-centred notion of being happy or doing what they want was not enough to constitute a successful life for their children. Likewise, their discourse revealed their clear hierarchical understanding of different qualifications and occupations. Thus, they suggested their children should achieve a certain level of academic qualifications and a career which is well matched with those qualifications in order to have a happy and successful future.

According to the Confucian beliefs, being obedient is considered to be the virtue of children and thus children are not supposed to question or challenge what their parents say to them. For instance, one example is Lang, a Master's degree holder who came to Britain six years ago from China to study, got married to a British man and is now an employed mother of one child aged two. Lang said of her parents "They don't care what we are good at ... what we want ... what they have is high expectations". In addition, Confucian principles give primacy to 'family and community over the 
individual, discipline and hierarchy over freedom and equality, and consensus and harmony over diversity and conflict' (Inoguchi and Shin 2009:184). In this context, following their parents' wishes is seen as virtuous as it contributes to the harmonious accomplishment of the family. Furthermore, Confucian traditions entail the notion that individuals should fulfil their duty as parents or children. In as much as providing good care and education was seen as a parent's duty, children are also expected to perform their duty by studying hard. As a result, in their stories East Asian cultural heritage continued to play a significant part in the way they brought up children in Britain.

By saying this, we are not arguing that Confucianism is the only factor affecting educational fever in East Asian countries. Doubtlessly, the intersection of a number of other socio, economic and political factors has contributed to these phenomena. However, what we claim here is that our interviewees perceived their attitude to the education of their children to be different from white British mothers because of their different cultural heritage which can be linked back to Confucianism.

\section{The importance of seniority}

Another predominant theme that emerged through the interviews was the significance placed on reverence for seniors. The hierarchical concept of Confucianism was applied to other human relationships in general and thus being respectful of older people was depicted as a crucial moral yardstick in East Asian culture. This seems evident in the account of Vicky, an employed mother of three children aged two, four and seven from Hong Kong, who came to Britain to study her Master's 13 years ago and got married to a second generation Chinese-British man:

I think Chinese tend to have more hierarchical concept about parental role. For example, you would never hear a Chinese or a person from Hong Kong call their mum and dad by their name, very rude. In England a lot of people do that...I always tell my children to address their friends' parents as auntie so and so and uncle so and so, and that is a very typical Chinese way of saying things.

Lang's account also illuminates similar attitudes:

Another key Chinese culture is respect for older generation. I always let my child to respect her grandparents. When her grandparents are around, I don't 
allow her and even my husband to start the meal until my parents, older ones sit around. And we don't call the first name of teachers.

As is evident from the above extracts, respect for seniors is represented as a deeply pervaded part of East Asian culture, which is ingrained in everyday practices, such as the way juniors addressed seniors and the customs around table manners. Addressing someone older by their first name was considered to be unacceptable in East Asian cultures where seniority was regarded as a significant measure of respect. Ensuring that their children address seniors as 'auntie' or 'uncle' or 'teacher' can therefore be seen as their attempts to retain their cultural heritage and pass it on to their children even in the use of English language. These accounts also suggest that there is an order of things in all human relationships and this should be preserved and protected through different generations. This ideological conviction of admiration for seniors and East Asian mothers' efforts to maintain it again emerge in the talk of Anne:

Here parents don't think it's rude if their child hits their heads. But I never. If my son hits his dad, I would react, "Ah! How dare you hit your dad?" like that. So I'm trying to teach him to respect his parents. In that respect, in terms of trying to teach our child to have good manners, I seem to be like that because I'm a Korean mother.

It is important to note here that 'good manners' in this context specifically means being polite to seniors, including parents. The above talk suggests that reverence for parents and seniors should be manifested in every aspect of East Asian people's lives, including the corporeal practice. In this sense, the importance placed on seniority in East Asian societies was reflected in a wide array of local customs, such as bodily practices as well as language. For instance, East Asian languages (e.g. Chinese, Japanese, Korean) are hierarchical in the sense that there exist different ways of referring to seniors or juniors, as illustrated in Lang's and Vicky's talk. Further, these accounts suggest that this strong belief was mirrored in everyday practice, in which children should display veneration for their parents and older people by treating them as the embodiment of authority and admiration. In this, mothers were portrayed as the lynchpin in instilling these values into their children. 


\section{Children as a mother's possession}

Another Confucian principle that emerged from the accounts of East Asian mothers was the discourse of children as a mother's belonging. This again reflected in the central tenet of Confucianism, in which a 'natural' hierarchy within human relationships was advocated (Oldstone-Moore 2003). On the basis of this notion, children are seen as not complete individuals, and their own thoughts and opinions are not yet developed, and thus have to rely on their mothers' decisions. This was presented as contrasting with the attitudes of white British mothers who were perceived to treat their children as separate individuals:

Song: British mothers treat their babies as an individual even if they're very young. However, in my country mothers consider their babies as their possession. For example, the thing I was shocked by, when I started working at nursery, mothers asked each baby, who didn't even speak properly, what they wanted to eat, whether they wanted to drink milk or juice or water. Compared to this, in my country mothers decide what to give to their babies.

According to Song's account, she believes there to be a taken-for-granted attitude among Korean mothers that children belonged to their mothers so mothers have a right to determine what is best for their children without asking their child's opinion. This way of treating children was resisted and depicted as not good by a few mothers and thus they suggested East Asians should learn 'the British way' of respecting children as individuals. Caroline said, 'They are more democratic to their children. We have a concept that children are children. But I know that's wrong so I try to respect his own idea, his own thoughts.' Consonant with this, Lang's accounts represent perceived problems of possessive attitudes from East Asian mothers towards their children:

English parents don't interfere that much about their children's lives. But Chinese parents they think they're parents, they can do everything for their children or you know that's my right to manage you. They've lost that respect for their children. You know children should get respect as well.

This again represented the perceived contrast between English (most often referred to by other participants as 'British') and Chinese parents: the former as respecting their children as independent individuals who were encouraged to find their own ways of life 
whereas the latter believing their children belonged to them and thus their rights to 'interfere' with the lives of their offspring. This kind of attitude towards their children was presented by some as not only showing the absence of respect for children but also hindering them from having independent minds. Again this was contrasted to an 'English' or 'British' alternative. Thus, East Asian mothers' regard for their children as their belonging was portrayed as the very source of spawning dependence in their children:

Lang: They [children] have to learn to think for themselves, make a decision for themselves. If the children heavily rely on their parents, they won't have the chance because the parents take the lead...English they're more independent.

In East Asian cultures mothers were described as excessively looking after their children or being over-protective and thus less relaxed about issues regarding child rearing. This was depicted by the talk of Francis, a mother of one child aged two from China, who originally came to Britain to accompany her Chinese husband, who was studying at a British university six years ago. She was studying a $\mathrm{PhD}$ at the time of the interview:

They [British mothers] are a lot more relaxed about everything. Particularly because of my upbringing I can't stand when they let their children crawl all over the floor or picking everything. How can you not care? On the other hand, I do admire that they're more relaxed, let them play with stuff, get wet in the rain and they're not afraid to let their children try out, explore. Whereas, we tend to worry about even if he is playing with painting or playing with sand, getting something in his eyes so yeah I'm trying to incorporate both and getting the balance between the two.

This account suggests that the deep-seated belief in children as their mother's possession render East Asian mothers excessively protective of their children. Hence, rather than letting children "try out" and learn as an independent individual, East Asian mothers were represented as always trying to protect their children as dependent parts of their mothers. The above talk also demonstrates the tensions the interviewee was experiencing between her experiences of 'East Asian culture(s)' and her exposure to and perceptions of 'British culture'. This simultaneously enabled her to compare herself with the perceived majority of British mothers and reflect on her own practices. As a 
result, some of the supposed 'British or English ways' of raising children became constructed by some as very good cultural aspects East Asian mothers tried to learn and embrace:

Lang: I saw an English mother carrying a pushchair on the pavement and there was a bump. When the pushchair reached it, the little boy inside fell off. And the boy just stood up and sat back to the chair [laughs...]. But, in China [if the same thing happened], "Oh!” You know it's a very big thing. The parent has to go to lift the child, "Are you all right?"

This reveals perceived stark differences in the way children are raised in Britain and China. But also Lang was highly impressed by the way the little boy and his mother reacted to the situation. For her, this epitomised an 'English way' of raising children as independent individuals from a very young age, which she constructed as strikingly different from her perception of the 'Chinese way'.

\section{Discussion and Conclusion}

This paper has suggested that the intersection of a mothering identity with class and East Asian cultural backgrounds creates unique experiences for middle-class East Asian mothers in Britain. As seen in the findings section, the respondents have diverse biographical backgrounds, in terms of nationality, the length of their settlement in Britain and reasons for migration, while they shared similar gender, class and ethnicity. However, despite such diversity, the interview data indicates rather similar responses from the participants. In this, particularly Confucian ideals, such as the importance of education and seniority, and children as their mother's possession, emerged as dominant intersecting factors that appear to have a continuing influence on the experiences of first generation East Asian mothers in this study. Even if they underwent changes in new social and cultural environments, East Asian cultural aspects remained significant in their personal stories of mothering.

In this regard, these findings differ from the existing literature examined earlier (Lim 2012), which indicates a more varied picture of mothering experiences of migrant women within similar cultures, depending on their country of origin. This may be in part because Lim's (2012) work did not focus on education. It may also be because, compared to this study, Lim's (2012) sampling was not exclusively middle-class, and had an equal balance of home-stay and employed mothers as well as participants across 
the three nations (Chinese, Japanese and South Korean). As such, more diverse voices might have come through in the work of Lim (2012).

In comparison with the interview data of Erel (2002), the findings of this paper might reflect considerable differences in migration trajectories between her Turkish participants and East Asian mothers in this study. For instance, dissimilar to Erel's participants, none of the East Asian women were forced to migrate due to social and familial pressures or 'chose' migration as a way of supporting their children. Rather, they either came to Britain to study or work as single women or to accompany their husbands, who were either pursuing higher educational qualifications or found wellpaid jobs in Britain. Also, all of the participants had a relatively secure life with the financial and social support of their husbands available, unlike many Turkish women in Erel's study. These different migration paths and class positions might explain why the stories of first generation East Asian women appear to question or challenge their traditional cultural heritage less than the Turkish migrant mothers in Erel's study. In addition, the majority of the participants in our study lived in ethnic communities where maintenance of their cultural heritages was relatively easy through local networking with other similar ethnic mothers.

As a possible result of these, the interaction of mothering with their East Asian cultural facets generated mothering practices that were perceived and represented as different from those of white British mothers. The key word here is perceived, because the interviewees compared their perceptions of East Asian culture(s) with a homogenised representation of an 'English' or 'British' culture. An important finding of our research, therefore, is that the discourse of the East Asian mothers we interviewed were strongly suggestive of their engagement with 'othering' of white British mothers, by identifying themselves with an East Asian identity while simultaneously dissociating from white British mothers. However, as Hall (1997) suggested, their perceived difference also entailed the positive portrayal of British mothers, which some East Asian mothers wanted to emulate. In our study 'othering' was carried out by the minority group as a means of comparing, confirming, justifying, and in some cases resisting their cultural heritage. In this sense it is their construction of the homogenised 'British other' that plays a significant part in their understanding of themselves as East Asians as well as in their practices of mothering. In other words, their subject position as East Asian mothers functioned as a very important factor constructing their mothering identities. 
The features of the cultural heritage the interviewees referred to are suggestive of a discernible trace of Confucianism, in which a strong hierarchical relationship between a parent and a child is espoused. Within this hierarchical understanding, the expectation is that individuals should fulfil their roles by complying with their given duties (Ebrey et al. 2006). Hence, mothers were described as having a duty to protect and provide their children with appropriate education and discipline while their children learnt and followed the teachings of their mothers, for example by working hard and showing respect for older people. In this sense, although the mothering practised by the women was highly labour intensive, the intensive mothering ideology they suggested came from their cultural heritage which was not child-centred. On the other hand, 'the British way' was represented as being concerned with the child's happiness and emotional wellbeing over and above their educational achievement, which could be linked to the child-centred principle of the intensive motherhood. For East Asian mothers the impact of British life on their mothering was perceived as a significant factor that concomitantly intersects with their mothering and ethnic identities. Their exposure to British cultural values and practices was portrayed by some as opening up new opportunities to look at and question the cultural norms they were accustomed to. In this regard, lack of respect for children as individual human beings was challenged by many respondents. Their discourses revealed that treating children as a mother's possession (e.g. making decisions for their children or being over-protective of them) was thought by some of the mothers to have a negative impact on children by preventing them from developing as independent individuals who have a full control over their own lives. Consequently, these mothers actively tried to incorporate positive aspects of what they believed to be 'British culture' into their mothering practices, rather than passively following Confucian cultural norms. Indeed, as this evidently suggests, East Asian women proactively participated in constructing their own identities and lives instead of being passive recipients of structural forces (Valentine 2007). Their location in Britain, even if related to an almost mythical notion of "the British or English way', appeared to provide them with more 'choices' in their identity formation. This allowed them to question certain parts of their cultural beliefs and norms and modify the way they raise their children to some degree. Thus, they did not merely become subjects of existing ideologies and beliefs but also active agents taking and reframing these in constructing and reconstructing their identities (Skinner 2011). In this sense, their position as East Asian women residing in Britain allowed them to 
construct a rather unique mothering identity, which was portrayed as different from white British mothers as well as their counterparts in East Asian societies by adding a new dimension to the intersection (Hall 1990).

To sum up, it could be argued that whilst Confucianism was still found to be a salient cultural facet that appears to have significant influence on East Asian mothers, its interplay with perceived 'British culture' may have produced qualitatively distinctive experiences for East Asian women in this particular study. In this sense, it is crucial to understand mothering identity as contextually specific processes. A caveat should be noted here though. By claiming the cultural impact of Confucianism on the identity construction of East Asian mothers, we are not attempting to homogenise East Asian countries. We are aware of diversities existing among these countries due to different economic and political developments. Nonetheless, the accounts of our research participants showed striking similarities, which we have linked back to Confucian ideals. Alongside this caveat, of course there are limitations to our selection of interviewees. For example, the relatively homogeneous class position of the respondents, their high level of qualifications and sourcing some of our respondents from after-school tutoring institutions, could also form part of an explanation for the strong support for education in our sample. However, in their stories the mothers did not refer to their middle-class roots as the reason, they had a particular perception of East Asian cultural values that they saw as intrinsic to their identity, predominantly juxtaposed not to an alternative class position but to an alternative cultural position. In their representations of their identities as mothers it was their cultural identities as East Asian, or indeed from particular countries in East Asia, that was put to the forefront. This may well reflect their status as migrant Others in Britain, mothers in East Asia may tell different stories more overtly related to class. Further research is needed comparing the narratives of East Asian (immigrant and non-immigrant) mothers from different class positions; as well as research that compares the narratives of East Asian mothers with a British sample to ascertain the extent to which the perceptions of difference held by our interviewees reflect actual differences in attitudes towards mothering. 


\section{References}

Andersen, M.L. and Hill-Collins, P. (2004) 'Shifting the center', in M. L. Andersen and P.H. Collins (eds) Race, class and gender: an anthology, $5^{\text {th }}$ ed. London: Thomson Learning, 15-22.

Anthias, F. and Yuval-Davis, N. (1983) 'Contexualising feminism: gender, ethnic and class divisions', Feminist review, 15: 62-75.

Bailey, L. (2000) 'Bridging home and work in the transition to motherhood: a discursive study', European journal of women's studies, 7: 53-70.

Brinton, M.C., Lee, Y-T. and Parish, W.L. (1995) 'Married women's employment in rapidly industrialising societies: examples from East Asia', The American journal of sociology, 100 (5): 1099-1130.

Chan, A. H-N. (2008) 'Life in happy land: using virtual space and doing motherhood in Hong Kong', Gender, place and culture, 15 (2): 169-188.

Chen, L.F. (1986) The Confucian way: a new systematic study of 'The four books', London: Routledge \& Kegan Paul plc.

Dale, A., Lindley, J. and Dex, S. (2006) 'A life-course perspective on ethnic differences in women's economic activity in Britain', European sociological review, 22 (4): 459476.

Devault, M. (1990) 'Talking and listening from women's standpoint: feminist strategies for interviewing and analysis', Social problems, 37 (1): 96-116.

Douglas, M. (1966) Purity and Danger. London: Routledge.

Ebrey, P.B., Walthall, A. and Palais, J.B. ( 2006) East Asia: a cultural, social, and political history, Boston: Houghton Mifflin Company.

Erel, U. (2002) 'Reconceptualising motherhood: experiences of migrant women from Turkey living in Germany', in D. Bryceson and U. Vuorela. (eds) The transnational family: new European frontiers and global networks. Oxford: Berg, 127-146. 
Erel, U. (2009) Migrant women transforming citizenship: life-stories from Britain and Germany. Farnham: Ashgate Publishing Ltd.

Freeden, M. (2003) Ideology: A very short introduction, Oxford: Oxford University Press.

Glenn, E.N. (1994) 'Social constructions of mothering: a thematic overview', in E.N. Glenn, G. Chang and L.R. Forcey (eds) Mothering: ideology, experience, and agency, London: Routledge, 1-29.

Hall, S. (1988) 'New Ethnicities', in Mercer, K. (ed) Black film/British cinema, ICA Document 7, London.

Hall, S. (1990) 'Cultural identity and diaspora', in Rutherford, J. (ed) Identity: community, culture, difference. London: Lawrence and Wishart, 222-237.

Hall, S. (1997) 'The spectacle of the 'Other', in S. Hall (ed) Representation: cultural representations and signifying practices, London: Sage Publications, 223-290.

Hays, S. (1996) The cultural contradictions of motherhood, London: Yale University Press.

Hirao, K. (2001) 'Mothers as the best teachers: Japanese motherhood and early childhood education', in Brinton, M. C. (ed) Women's working lives in East Asia. Stanford, CA: Stanford University Press, 180-203.

Inoguchi, T. and Shin, D.C. (2009) 'The quality of life in Confucian Asia: from physical welfare to subjective well-being', Social indicators research, 92: 183-190.

Jordan, B. (1993) 'Authoritative knowledge and its construction', in R. E. Davis-Floyd and C. Sargent (eds) Childbirth and authoritative knowledge: cross-cultural perspectives. Berkeley: University of California Press.

Keum, J-T. (2003) Understanding Korean Confucianism, $2^{\text {nd }}$ ed. Paju, South Korea: Korean Academic Information. (in Korean).

Lau, D.C. (1979) Confucius: the analects, London: Penguin Books. 
Lawler, S. (1996) 'Motherhood and Identity', in T. Cosslett, A. Easton and P.

Summerfield (eds) Women, Power and Resistance: an Introduction to Women's Studies, Buckingham: Open University Press, 153-164.

Lim, H-J. (2012) The intersection of motherhood identity with culture and class: a qualitative study of East Asian mothers in England, Thesis (PhD). University of Bath.

Miller, T. (2005) Making sense of motherhood: a narrative approach. Cambridge:

Cambridge University Press.

Mishler, E. G. (1986) Research interviewing: context and narrative. Cambridge,

Massachusetts: Harvard University Press.

Oldstone-Moore, J. (2003) Understanding Confucianism, London: Duncan Baird Publishers.

Skinner, T. (2011) 'Dyslexia, mothering and work: intersecting identities, reframing, 'drowning' and resistance', Disability and society, 26 (2):125-137.

Skinner, T. (2012) 'Women's perceptions of how their dyslexia impacts on their mothering', Disability and Society, 1-15.

Stenbacka, C. (2001) 'Qualitative research requires quality concepts of its own', Management decision, 39 (7): 551-555.

Sung, S. (2003) 'Women reconciling paid and unpaid work in a Confucian welfare state: the case of South Korea', Social policy and administration, 37 (4): 342-360.

Thomson, R., Kehily, M. J., Hadfield, L. and Sharpe, S. (2011) Making modern mothers. Bristol: The Policy Press.

Valentine, G. (2007) 'Theorizing and researching intersectionality: a challenge for feminist geography', The professional geographer, 59 (1): 10-21.

Vincent, C., Ball, S.J. and Pietkainen, S. (2004) 'Metropolitan mothers: mothers, mothering and paid work', Women's studies international forum, 27: 571-587.

Williams, R. (1981) Culture. Glasgow: William Collins Sons \& Co, Ltd. 
Wu, S-Y. (2007) Motherhood: negotiating paid work and childcare; a comparative study between two different generations in Taiwan, Thesis (PhD). University of Bath. Yi, C-C. and Nauck, B. (2006) 'Gender, marriage and family support in East Asian Families', Current sociology, 54 (2): 155-163. 